\title{
Chondrocyte Viability in Fresh and Frozen Large Human Osteochondral Allografts: Effect of Cryoprotective Agents
}

\author{
F. Judas, S. Rosa, L. Teixeira, C. Lopes, and A. Ferreira Mendes
}

\begin{abstract}
Chondrocyte survival is a major goal for the effective storage and clinical performance of human osteochondral allografts. The majority of animal and human cryopreservation studies conducted so far have been performed in small osteochondral cylinders. Using human tibial plateaus as a model for large osteochondral pieces, this work sought to evaluate the cryoprotective efficiency of glycerol and dimethylsulfoxide (DMSO), and to identify cryopreservation conditions suitable for use in tissue banks. Human tibial plateaus harvested from 7 cadaveric tissue donors were incubated in the presence or absence of cryoprotective agents (CPA): $10 \%$ or $15 \%$ glycerol and 10\% DMSO in a Ham F-12 nutrient mixture. Chondrocyte viability was assessed immediately after thawing, using the MTT reduction assay and a fluorescence microscopic method. The tibial plateaus frozen in the absence of CPA showed a significant decrease in chondrocyte viability. The use of CPA significantly increased chondrocyte viability compared with cartilage frozen without CPA (nearly $50 \%$ versus $80 \%$ living chondrocytes with $10 \%$ glycerol versus $10 \%$ DMSO, respectively) relative to that in fresh cartilage. In this regard, $10 \%$ DMSO was slightly more effective than either $10 \%$ or $15 \%$ glycerol, eliciting the recovery of approximately $15 \%$ relative to the living chondrocyte content in fresh cartilage. In all conditions, fluorescence microscopic studies showed that surviving chondrocytes were restricted to the superficial cartilage layer. Human tibial plateaus seemed to be a good experimental model to establish cryopreservation methods applicable to large human osteochondral pieces in tissue banks.
\end{abstract}

\begin{abstract}
$\mathrm{A}^{\mathrm{n}}$ RTICULAR CARTILAGE INJURY is challenging to treat because of limited intrinsic healing capacity. Although the natural history of isolated lesions is unknown, it is generally accepted that articular cartilage injury may predispose the involved joint to accelerated degeneration and osteoarthritis. ${ }^{1,2}$ Chondral and osteochondral injuries involving the knee are common. A review of 31,000 arthroscopic procedures reported articular cartilage lesions in $63 \%,{ }^{3}$ whereas another work involving 1000 consecutive arthroscopies reported the incidence of localized chondral and osteochondral lesions to be $19 \% .^{4}$ The unsuitability of total knee arthroplasty for young, active patients has provided the stimulus to search for alternative treatments for biological resurfacing of the articular cartilage. Debate still persists about the best treatment for chondral and osteochondral lesions.

Current treatments for damaged articular cartilage, including debridement, drilling, and abrasion of the defects, microfractures, mosaicplasty, periosteal and perichondral
\end{abstract}

resurfacing, synthetic matrices, and growth factors, often produce fibrocartilage. ${ }^{5}$ Autologous chondrocyte transplantation, although promising, has not proved superior to the microfracture procedure. ${ }^{6}$ Alternative cell sources, such as bone marrow-derived mesenchymal stem cells, are also being investigated to reduce the possibility of donor-site morbidity. ${ }^{7}$ Despite all these attempts, no method has yet been able to consistently reproduce normal hyaline cartilage. The best treatment in the long term is still unknown.

From the Orthopaedics Department of Coimbra University Hospitals and Faculty of Medicine (F.J., L.T.), and Center for Neuroscience and Cell Biology and Faculty of Pharmacy (S.R., C.L., A.F.M.), University of Coimbra, Coimbra, Portugal.

Address reprint requests to Fernando Judas, MD, PhD, Orthopaedics Department of Coimbra University Hospitals (HUC), Praceta Prof. Mota Pinto, Bloco de Celas, 3000 Coimbra, Portugal. E-mail: fernandojudas@gmail.com

$0041-1345 / 07 / \$-$ see front matter doi:10.1016/j.transproceed.2007.07.028 
Osteochondral grafts are increasingly employed as a means of biological resurfacing for articular cartilage defects, effectively delaying the progression of arthritis. ${ }^{8}$ Lack of sufficient donor tissue and morbidity of the donor site and difficulty to match the contours of the graft and the recipient site are disadvantages inherent to the use of osteochondral autografts. In contrast, the use of allografts, obtained from cadaveric donors, overcomes these difficulties, allowing the treatment of large cartilage defects. ${ }^{9,10}$

Two types of osteochondral allografts are currently used. Frozen allografts have the advantage of enabling size matching of the allograft and the recipient, screening of infectious diseases of the donor, which have to be ruled out for safe transplantation, and transportation of tissues to distant locations. ${ }^{11-13}$ However, compared with fresh osteochondral allografts the survival and clinical outcome of frozen tissue poor with fibrocartilage formation, chondromalacia, and loss of cartilage surfaces occurring frequently after implantation. ${ }^{11,13,14}$ These complications lead to a graft failure rate that ranges from $10 \%$ to $50 \% .{ }^{15}$ However, the use of fresh allografts is limited by the intermittent availability of appropriate material and the necessity to transplant the tissue within a relatively short time after harvesting, ${ }^{16}$ usually no longer than 2 weeks. ${ }^{17}$ Many studies support the notion that the function of transplanted osteochondral grafts is proportional to their content of living cells, ${ }^{10,13,18}$ since chondrocytes are essential to maintain the integrity of the cartilage matrix. ${ }^{14}$ Any injury that kills even a small number of cells can have severe consequences on cartilage integrity and durability. ${ }^{10}$

Isolated chondrocytes are effectively protected from the damaging effects of freezing by cryoprotective agents (CPA), such as glycerol or dimethylsulfoxide (DMSO). ${ }^{15,19}$ However, freezing of intact articular cartilage as osteochondral pieces, even in the presence of CPA, seriously compromises chondrocyte viability. ${ }^{20,21}$ Therefore, developing cryopreservation methods that sustain chondrocyte survival is a major goal for the effective storage and clinical use of allograft cartilage in tissue banks, with direct implications for the fields of biomaterials and cryobiology. The majority of cryopreservation studies performed to date have used small osteochondral cylinders from various animal species, making it difficult to extrapolate the findings to large human osteochondral pieces. Thus, using human tibial plateaus as a model for large osteochondral pieces, this work sought to evaluate the cryoprotective efficiency of glycerol and DMSO, and to identify cryopreservation conditions suitable for use in tissue banks.

\section{MATERIALS AND METHODS}

Human tibial plateaus were harvested from 7 cadaveric tissue donors ( 5 males and 2 females, average donor age, $33.2 \pm 11.4$ years) within 24 hours of death in strictly aseptic conditions according to the standards of the HUC Bone and Tissue Bank and the Portuguese Transplantation Organization. ${ }^{22}$ Articular cartilage from all donors appeared grossly normal without signs of fibrilla- tion or other lesions. The causes of death were severe head injury (49) and intracranial hemorrhage (3).

The lateral and medial tibial plateaus from each cadaveric tissue donor were incubated in the presence or absence of CPA $(10 \%$ or $15 \%$ glycerol, $10 \%$ DMSO in Ham F-12 nutrient mixture) at $37^{\circ} \mathrm{C}$ for 30 or 60 minutes at room temperature and then frozen at $-20^{\circ} \mathrm{C} / 24$ hours. After the initial cooling, the osteochondral pieces were transferred to a biofreezer at $-80^{\circ} \mathrm{C}$ and kept for a maximum of 2 months. Thawing was achieved by immersion in Ham F-12 nutrient mixture at $37^{\circ} \mathrm{C}$ for 1 hour. From each tibial plateau, 12 cylinders were cut with a trephine and used to assess chondrocyte viability in situ immediately after thawing. Two methods were used: (1) an adaptation of the methylthiazolyldiphenyl-tetrazolium bromide (MTT: Sigma, Mo, USA) ${ }^{23}$ reduction assay, which is a quantitative method that measures the reducing capacity of living cells; and (2) a fluorescence microscopy-based method in which cartilage sections are stained with the fluorophores calcein AM and propidium iodide that distinguish living from dead cells, respectively, based on membrane integrity. Ten of the 12 cylinders collected from each tibial plateau were weighed and incubated in Ham F-12 nutrient mixture (Sigma, Mo, USA) containing $1 \mathrm{mg} / \mathrm{mL}$ MTT for 1 hour at $37^{\circ} \mathrm{C}$. The dark blue crystals of formazan produced by reduction of the MTT salt were dissolved in acidified isopropanol, and quantified in an automatic plate reader (SLT, Austria) set at a test wavelength of $570 \mathrm{~nm}$ and a reference wavelength of $620 \mathrm{~nm}$. The remaining 2 cylinders were incubated at $37^{\circ} \mathrm{C}$ for 30 minutes in a solution containing $5 \mu \mathrm{mol} / \mathrm{L}$ calcein $\mathrm{AM}$ (Sigma, Mo, USA) and $5 \mu \mathrm{g} / \mathrm{mL}$ propidium iodide (Sigma, Mo, USA) in PBS. Cryostat sections ( $30 \mu \mathrm{m}$ thick) obtained from each cylinder were viewed under a fluorescence microscope. The proportion and distribution of intact and disrupted cells were evaluated for each experimental condition and compared with cartilage exposed to the nutrient mixture alone and to fresh cartilage. Where applicable, statistical analysis was performed using the Student $t$ test. Results were considered significant at $P<.05$.

\section{RESULTS}

Evaluation of chondrocyte viability immediately after exposure of the tibial plateaus to the CPA showed that none of the agents had toxic effects under the tested conditions (results not shown). After freezing/thawing, the tibial plateaus showed a significant decrease in chondrocyte viability, relative to fresh cartilage. The results presented in Figure 1 show that in the absence of CPA, approximately $10 \%$ of the chondrocytes in fresh cartilage survived freezing thawing. This value was higher than expected, probably due to the use, before freezing, of a nutrient mixture, instead of a saline or saline-based solution. In contrast, chondrocyte viability was significantly enhanced by the use of CPA. In fact, preincubation of the tibial plateaus in Ham F-12 with $10 \%$ or $15 \%$ glycerol elicited an approximately $40 \%$ increase in cell viability relative to that of the controls, namely, tibial plateaus frozen after preincubation in the nutrient mixture alone. The increase was even more significant (approximately 80\%) among tibial plateaus treated with $10 \%$ DMSO. When cell viability was compared with that in fresh cartilage, the protective effect of glycerol and DMSO was also evident. As shown in Figure 1, 10\% DMSO was the most effective cryoprotective solution, eliciting the recovery of nearly $15 \%$ of the cartilage chondrocytes, 


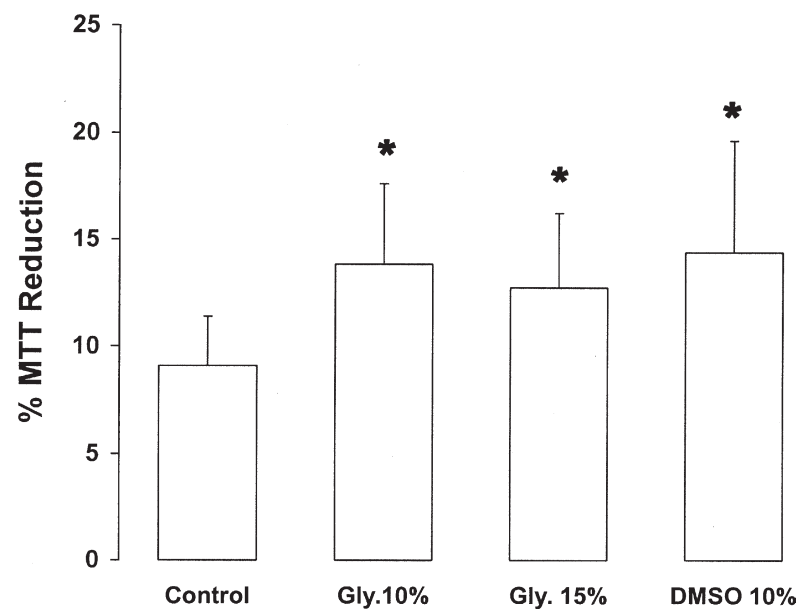

Fig 1. Chondrocyte viability assessed by the MTT reduction assay. Tibial plateaus were incubated with Ham F-12 nutrient mixture alone (control) or with the indicated concentrations of glycerol and DMSO for 30 minutes at $37^{\circ} \mathrm{C}(10 \%$ glycerol and $10 \% \mathrm{DMSO})$ or for 1 hour at room temperature (15\% glycerol) and immediately removed and frozen as indicated in the Materials and Methods section. Chondrocyte viability was assessed immediately after thawing the tibial plateaus, and the results were expressed as a percentage of the amount of $\mathrm{MTT}$ reduced by the chondrocytes present in fresh tibial plateau cartilage. The results shown for each condition represent the mean values \pm SD of 7 different experiments, each performed in duplicate, using 5 cartilage cylinders in each replicate. ${ }^{*} P<.05$.

relative to the living cell content in fresh cartilage, whereas $10 \%$ and $15 \%$ glycerol solutions were slightly less effective (14\% and $13 \%$ living cells, respectively). These results agreed with those obtained by fluorescence microscopy of cartilage sections stained with calcein AM and propidium iodide (results not shown), which showed that living chondrocytes were restricted to the superficial cartilage layer, indicating that the CPA did not penetrate the entire depth of the cartilage.

\section{DISCUSSION}

The results obtained in the present study indicated that the use of a nutrient mixture, containing a balanced amount of glucose, amino acids, vitamins, electrolytes, oligoelements, and other nutrients, by itself allowed the recovery of a greater percentage of living chondrocytes than the use of saline or saline-based buffers, which have been reported to promote the recovery of only few living chondrocytes or none at all. ${ }^{21}$ Moreover, this study also showed that the use of CPA, despite increasing the recovery of living chondrocytes after freezing/thawing, still did not completely prevent cryoinjury to the articular cartilage. A major reason for the limited efficacy of CPA is their inherent toxicity which limits the duration, temperature, and concentration of cartilage exposure. Thus, identification of a less toxic CPA would allow longer exposure times and, consequently, more effective cryoprotection of the chondrocytes in the entire depth of the cartilage. A possible strategy to achieve this purpose is the combination of various CPA at reduced individual concentrations. Another strategy is the identification of new, more effective and less toxic CPA. In contrast, it is still not clear whether chondrocytes that survive cryopreservation effectively maintain their metabolic activity over time and, thus, are still capable of maintaining cartilage integrity. Current work in our laboratory is attempting to address these questions.

Furthermore, the percentage of living chondrocytes retrieved with the various CPA used in this study was apparently lower than that reported in other studies. ${ }^{10,20,21,24-26} \mathrm{~A}$ probable explanation was that, in those studies, small osteochondral cylinders were harvested from the distal femoral condyles of various animal species or from human cadaveric donors, exposed afterward to the CPA solutions and subsequently frozen. The small size and large total surface area of those cylinders facilitate the diffusion of CPA, thus allowing recovery of a greater percentage of living chondrocytes than that observe in this study. However, in tissue banks, the pieces that have to be cryopreserved and stored for later use as donor tissue are quite large, making it difficult to extrapolate and adapt the findings to large human osteochondral pieces, like the distal femur or the proximal humerus. The results presented herein indicated that human tibial plateaus present approximately the same problems for the diffusion of CPA through the entire depth of the cartilage as those posed by whole bone. Thus, human tibial plateaus are a good experimental model to establish cryopreservation methods applicable to large human osteochondral pieces in tissue banks.

\section{REFERENCES}

1. Bentley G, Manktelow ARJ: Repair of articular cartilage defects in the knee. In: Surgical Techniques in Orthopaedics and Traumatology. Editions Scientifique et Médicales Elsevier (SAS) Paris; 2001, p 9

2. Twyman RS, Desai K: Osteochondritis dissecans of the knee: a long-term study. J Bone Jt Surg 73B:6461, 1991

3. Curl WW, Krome J, Gordon ES, et al: Cartilage injuries: a review of 31,516 knee arthroscopies. Arthroscopy 13:456, 1997

4. Hjelle K, Solheim E, Strand T, et al: Articular cartilage defects in 1,000 knee arthroscopies. Arthroscopy 18:730, 2002

5. Buckwalter JA: Articular cartilage injuries. Clin Orthop 42: 21, 2002

6. Knutsen G, Engebretsen L, Ludvigsen TC, et al: Autologous chondrocyte implantation compared with microfracture in the knee. J Bone Jt Surg Am 86A:455, 2004

7. Wakitani S, Imoto K, Yamamoto T, et al: Human autologous culture expanded bone marrow mesenchymal cell transplantation for repair of cartilage defects in osteoarthritic knees. Osteoarthritis Cartilage 10:199, 2002

8. Weinand C, Peretti GM, Adams SB Jr, et al: Healing potential of transplanted allogeneic chondrocytes of three different sources in lesions of the avascular zone of the meniscus: a pilot study. Arch Orthop Trauma Surg (online publication) DOI 10.1007/s00402-005-01007, 2006

9. Frenkel SR, Kubiak EN, Truncale KG: The repair response to osteochondral implant types in a rabbit model. Cell Tissue Bank 7:29, 2006 
10. Gole MD, Poulsen D, Marzo JM, et al: Chondrocyte viability in press-fit cryopreserved osteochondral allografts. J Orthop Res 22:781, 2004

11. Csönge L, Bravo D, Newman-Gage H, et al: Banking of osteochondral allografts, part I. Preservation of chondrocyte viability during long-term storage. Cell Tissue Bank 3:161, 2002

12. Csönge L, Bravo D, Newman-Gage H, et al: Banking of osteochondral allografts, part II. Viability assays adapted for osteochondral and cartilage studies. Cell Tissue Bank 3:151, 2002

13. Vangsness CT Jr, Garcia IA, Mills CR, et al: Allograft transplantation in the knee: tissue regulation, procurement, processing, and sterilization. Am J Sports Med 31:474, 2003

14. Enneking WF, Mindell ER: Observations on massive retrieved human allografts. J Bone Jt Surg Am 73:1123, 1991

15. Tomford WW, Springfield DS, Mankin HJ: Fresh and frozen articular cartilage allografts. Orthopedics 15:1183, 1992

16. Chu CR, Convery FR, Akeson WH, et al: Articular cartilage transplantation. Clinical results in the knee. Clin Orthop Relat Res. 360:159, 1999

17. Williams SK, Amiel D, Ball ST, et al: Prolonged storage effects on the articular cartilage of fresh human osteochondral allografts. J Bone Jt Surg Am 85:2111, 2003

18. Friedlaender GE, Strong MD, Tomford WW, et al: Longterm follow-up of patients with osteochondral allografts. A corre- lation between immunologic responses and clinical outcome. Orthop Clin North Am 30:583, 1999

19. Almqvist KF, Wang L, Broddelez C, et al: Biological freezing of human articular chondrocytes. Osteoarthritis Cartilage 9:341, 2001

20. Muldrew K, Novak K, Studholme C, et al: Transplantation of articular cartilage following a step-cooling cryopreservation protocol. Cryobiology 43:260, 2001

21. Ohlendorf C, Tomford WW, Mankin HJ: Chondrocyte survival in cryopreserved osteochondral articular cartilage. J Orthop Res 14:413, 1996

22. Judas F, Teixeira L, Proença A: Coimbra University Hospitals Bone and Tissue Bank: 22 years of experience. Transplant Proc 37:2799, 2005

23. Mosmann T: Rapid colorimetric assay for cellular growth and survival: application to proliferation and cytotoxicity assays. J Immunol Method 65:55, 1983

24. Jomha NM, Lavoie G, Muldrew K, et al: Cryopreservation of intact human articular cartilage. J Orthop Res 20:1253, 2002

25. Marco F, Leon C, Lopez-Oliva F, et al: Intact articular cartilage cryopreservation. In vivo evaluation. Clin Orthop 283:11, 1992

26. Muir H: The chondrocyte, architect of cartilage. Biomechanics, structure, function and molecular biology of cartilage matrix macromolecules. BioEssays 17:1039, 1995 